\title{
Theory vs Practice: Should Primary Care Practice Take on Social Determinants of Health Now? Yes.
}

\author{
Artbur Kaufman, MD \\ University of New Mexico, Albuquerque, New Mexico \\ Ann Fam Med 2016;14:100-101. doi: 10.1370/afm.1915.
}

$\mathrm{O}$ $\mathrm{f}$ all ethnic groups in New Mexico, Native Americans have some of the best screening and treatment for diabetes, yet have by far the worst outcomes from that disease-kidney failure, amputations, blindness. High-quality care cannot adequately compensate for decades of low income, low educational achievement, poor nutrition, poor housing, and social marginalization-all social determinants of health $(\mathrm{SDH})$. With appropriate transformation, primary care practices are well-suited to address SDH.

Physicians recognize the importance of $\mathrm{SDH}$ in their practices. Of 1,000 physicians surveyed, 4 out of 5 found $\mathrm{SDH}$ as important as medical needs, but lacked confidence in addressing these social needs, and believed their patients' health suffered when the needs were not addressed. ${ }^{1}$ But how is this recognition to be addressed in practice?

The national environment, especially due to the Patient Protection and Affordable Care Act (ACA), provided support for this major effort. For example, the patient-centered medical home $(\mathrm{PCMH})$ is being reconceived on a broader scale as a communitycentered health home, ${ }^{2}$ featuring a more communityfocused, social-ecologic model of health and disease including different community stakeholders and sectors which influence health. And health extension, found in Section 5405 of the ACA, was fashioned upon the decentralized cooperative extension service model found in the agricultural sector, linking health science

Conflict of interest: author reports none

\section{CORRESPONDING AUTHOR}

Arthur Kaufman, MD

Family and Community Medicine

University of New Mexico

MSC 095040

1 University of New Mexico

Albuquerque, NM 87131

akaufman@salud.unm.edu center resources with community health priorities, including $\mathrm{SDH}^{3,4}$

What are the objections to incorporating SDH into medical care in general and into primary care in particular? First, some are concerned that physicians are "not paid to do this." Yet incentives have emerged in recent years to invest upstream. These incentives were triggered by the accountable care organizations, bundled payments, capitation, and, more recently, penalties to hospitals from Medicare for 30-day readmissions-all pressures for health systems to invest in prevention.

Another objection is that SDH are not in a physician's scope of service. Asking SDH questions takes too much time. And if a social need is uncovered, what can be done about it? Because primary care seems barraged with ever more requirements, paperwork, dynamic documentation, and adapting to ICD-10 coding, this is hardly the time, some warn, to burden primary care clinicians with yet more requirements.

Expanding the role of primary care physicians, however, toward addressing evidence-based prevention screening and interventions is feasible if the health team is expanded. Garg and colleagues from Johns Hopkins screened for SDH within the patient-centered medical home during the pediatric well-child visit while collocating community-based resources. ${ }^{5}$ Perhaps the most significant addition to the team are community health workers who spend more time addressing the SDH than do other team members. And today, evidence supports a measurable health benefit from primary care teams addressing social determinants. For example, medical assistants at all University of New Mexico's primary care clinics ask all patients SDH questions. This followed a preliminary pilot in which 3,048 patients, almost all seen at 3 university and 1 local federally qualified health center, were asked 11 questions related to income, education, food, housing, transportation, utilities, safety, and substance abuse over a 90-day period. Forty-six percent screened positive for at least 1 area of social need and $63 \%$ of those 
had multiple needs. ${ }^{6}$ As a consequence, 2 to 3 clinicbased community health workers were then hired for each of the 7 primary care clinics to address such needs. Primary care physicians laud this development's impact of unburdening them of having to address complex social needs presented by their patients.

Payers have also incented primary care clinicians to address SDH. Community health workers working with 448 high-risk, high-cost primary care Medicaidmanaged care enrollees over a 6 -month period demonstrated a significant increase in use of primary care services with a significant drop in emergency room visits, hospitalizations, and drug use. ${ }^{7}$ The managed care organizations estimated a return on investment of 4 to 1 .

The Accreditation Council for Graduate Medical Education is now requiring all residency programs to address health disparities through quality-improvement activities. In New Mexico, family medicine residents work in community clinics staffed by local community health workers. ${ }^{8}$ There, residents' education is enhanced by inter-professional teamwork, cultural proficiency, effective communication, provision of costconscious care, and advocating both for individual and community.

In conclusion, primary care has not only the evidence to justify investments in addressing $\mathrm{SDH}$, but also a growing, supportive health care climate which provides funding strategies to address those needs by broadening the clinical care team.
To read or post commentaries in response to this article, see it online at http://www.annfammed.org/content/14/2/100.

Key words: social determinants of health; primary healthcare; community health workers

Submitted January 9, 2016; submitted, revised, January 9, 2016; accepted January 20, 2016.

\section{REFERENCES}

1. Fenton M. Health care's blind side: the overlooked connection between social needs and good health. The Robert Wood Johnson Foundation. http://www.rwjf.org/en/library/research/2011/12/healthcare-s-blind-side.html. Published Dec 2011.

2. Mikkelsen L, Cohen L, Frankowski S. Community-centered health homes: engaging health care in building health communities. National Civic Review. 2014;103(I, special issue):57-59.

3. Kaufman A, Powell W, Alfero C, et al. Health extension in new Mexico: an academic health center and the social determinants of disease. Ann Fam Med. 2010;8(1):73-81.

4. Phillips RL Jr, Kaufman A, Mold JW, et al. The primary care extension program: a catalyst for change. Ann Fam Med. 2013;11(2):173-178.

5. Garg A, Jack B, Zuckerman B. Addressing the social determinants of health within the patient-centered medical home: lessons from pediatrics. JAMA. 2013;309(19):2001-2002.

6. Page-Reeves J, Kaufman W, Bleecker M, et al. Addressing social determinants of health in a clinic setting in New Mexico. J Am Board Fam Med. In press.

7. Johnson D, Saavedra P, Sun E, et al. Community health workers and medicaid managed care in New Mexico. J Community Health. 2012;37(3):563-571.

8. McCalmont K, Norris J, Garzon A, et al. Community health workers and family medicine resident education: addressing the social determinants of health. Fam Med. In press. 